\title{
Joining the dots: neurobiological links in a functional analysis of depression
}

\author{
Christopher F Sharpley ${ }^{1 * \dagger}$, Vicki Bitsika ${ }^{2 \dagger}$
}

\begin{abstract}
Depression is one of the major contributors to the Total Disease Burden and afflicts about one-sixth of Western populations. One of the most effective treatments for depression focuses upon analysis of causal chains in overt behaviour, but does not include brain-related phenomena as steps along these causal pathways. Recent research findings regarding the neurobiological concomitants of depressive behaviour suggest a sequence of structural and functional alterations to the brain which may also produce a beneficial outcome for the depressed individual-that of adaptive withdrawal from uncontrollable aversive stressors. Linking these brain-based explanations to models of observable contingencies for depressive behaviour can provide a comprehensive explanation of how depressive behaviour occurs and why it persists in many patients.
\end{abstract}

\section{Background}

Principally via its harmful effects on health, relationships and cognitive performance [1-4], depression is the principal contributor to the Total Disease Burden [5] and predicted to become the second leading cause of mental illness by 2020 [6,7]. As an indication of the significance of this problem, it has been shown that depression poses as great a risk for mortality as does smoking, even when controlling for blood pressure, alcohol intake, cholesterol and social status [8]. The incidence of having a major depressive episode during one's lifetime is $17 \%$ in the USA and 13\% in Europe [9-11], suggesting that nearly one in five people may suffer this disorder. Together, these data argue for the urgency of research into effective treatments for depression, particularly those that are based upon explanations of depression that encompass both externally-observable behaviour and also brain function.

\section{Treatment of depression}

Both pharmacological and psychological treatments have been shown to be effective with various populations of depressed persons [12,13], with some data suggesting a reciprocal relationship between these two

\footnotetext{
* Correspondence: csharpley@onthenet.com.au

+ Contributed equally

'Brain-Behaviour Research Group, University of New England, New South

Wales, Australia

Full list of author information is available at the end of the article
}

approaches $[14,15]$. One form of psychological treatment that has a strong evidence basis and which is relevant to a discussion of the links between brain and behaviour in explaining the 'causality' of depression is that which is commonly referred to as "Behavioural Functional Analysis". This process underlies many successful psychological treatments [e.g., 16, 17-22], and is characterised by a focus upon the purpose or outcome of behaviour for the organism exhibiting it [21], information that is acquired by examining the antecedents and consequences of a particular behaviour and determining the links between these two aspects. As well as being successful with mild to moderate depression, there are also data which support the use of some of these functional analytic approaches with Major Depressive Disorder (MDD) [23], indicating that this form of psychotherapy may be at least as effective as antidepressant medication for reducing the symptoms of acute depression [24-26].

This process of analysing the antecedents and consequences of overt behaviours as causal vectors for depression is the central theme of Behavioural Functional Analysis, and may reveal the outcomes of depressive behaviour for the individual exhibiting it $[27,28]$. For example, depressive behaviour may (unwittingly) be negatively reinforced by avoidance of, or escape from, threats, and positively reinforced by social attention and help from peers, relatives or (in the case of humans) professionals who focus upon the depressed individual's suffering and attempt to alleviate it by various means 
[29]. These consequences for depressive behaviour may provide powerful contingencies for maintenance of the depressive symptomatology, at least for a period of time. As noted 150 years ago by Charles Darwin (p. 51):

Pain or suffering of any kind, if long continued, causes depression and lessens the power of action; yet, it is well adapted to make a creature guard itself against any great or sudden evil" [30].

Thus, depressive behaviour may provide a (temporary) benefit for individuals when they encounter uncontrollably aversive environments, and this model is congruent with the hypothesis advanced several decades ago by Ferster [31], Dougher and Hackbert [32] and most recently elaborated by Kanter, Busch, Weeks, and Landes [33] that depressive symptomatology falls within the spectrum of withdrawal from contact with an uncontrollably aversive environment [29]. Although the "adaptive" nature of that withdrawal may become maladaptive over time, the initial function of the depressive behaviours is adaptive for the person exhibiting it.

This perspective is parallel to the notion of "sickness behaviour" in humans and other animals as postulated by Dantzer, O'Connor et al. [34], who identified symptoms such as feeling feverish and nauseous, experiencing a lack of appetite, sleep disturbance, loss of interest in social and physical environments, anhedonia, and being easily fatigued, as normal responses to infection and which are triggered by pro-inflammatory cytokines such as IL- $1 \beta$ and TNF- $\alpha$. That is, as well as coordinating the local inflammatory response to infection, IL-1 $\beta$ and TNF- $\alpha$ also act on receptors spread throughout several regions of the brain (e.g., dentate gyrus, pyramidal cell layers of the hippocampus, anterior pituitary gland, hypothalamus and others $[35,36])$ to cause these sickness behaviours. In terms of their function, these sickness behaviours help infected individuals cope with their illness by changing their perceptions of their state and their reactions to it.

However, in some cases, those sickness behaviours may be so severe as to constitute the necessary symptomatology for a diagnosis of MDD by way of the social withdrawal that characterizes cytokine-induced sickness behaviour and which also underlies all depressive symptomatology [29]. Dantzer, et al. reported that administration of IL- $1 \beta$ or TNF- $\alpha$ to rats induced sickness behaviour such as withdrawal from social activity, reduced motor behaviour, reduced water and food intake, increased fatigue, altered cognition and changed sleep patterns. The rats "stay in a corner of their cage in hunched posture" (p. 48), reminiscent of the behaviour of many humans with MDD [37]. When applied to the specific MDD symptoms of sadness, anhedonia, sleep disturbance, appetite change and cognitive impairment, these symptoms may be seen to represent a biological response pattern that translates into the psychological behaviours of low self-esteem, hopelessness and helplessness. Although these may be unpleasant, this withdrawal from aversive stimuli and environments that characterises depression has been described as "adaptive" because it also reduces the quantum of noxious stimuli to which the organism is exposed $[38,39]$. An important aspect of the mechanism underlying this withdrawal is the conviction on the part of depressive individuals that they have no real control over the unpleasant experience that is occurring to them $[38,39]$ and therefore are left with a single response that will reduce distress-withdrawal from the environment that is causing it. In this way (and as indicated by Darwin), depression may perform a valuable function for the depressed individual $[40,41]$ by reducing unpleasantness in the only way possible at that time.

However, psychological treatments for depression that use Functional Analysis (to at least some extent) have focussed almost exclusively upon the readily observable (i.e., overt) environmental antecedents and consequences for depressive behaviour. Explanations based upon those data alone are incomplete because they do not describe the less-easily observed neurobiological links between the organism experiencing the genetic and environmental stimuli and the later emergence of depressive behaviour. A description of those neurobiological links to depression would not only provide a more complete and logical description of the development of depressive behaviour as a typical response to overpowering and aversive environmental stress, it could also inform treatment of depression.

From a biological standpoint, while some of the antecedents for depression are genetic [42-45], one of the strongest predictors of depression is stress in the form of excessive demanding challenges across a range of areas [46]. Stress acts through a variety of physiological causal pathways which may undermine an individual's ability to withstand it $[47,48]$ so that, over prolonged time, depressive symptoms occur. Those causal pathways include not only the form of the externally-observable behaviour, the function of that behaviour (in terms of outcomes gained by the organism exhibiting it), but also a consideration of how brain responses act in concert with those behaviours to produce an overall valued outcome for the depressed individual.

Therefore, this paper addresses the issue of linking depressive behaviour with brain function and (a) describes the neurobiological steps between onset of an environmental stressor and the later development of depressive behaviour, (b) explains how these steps function for the benefit of the depressed individual, and (c) raises some implications for treatment options. 


\section{The neurobiology of depression}

There are several subtypes of depression, but the most common is unipolar depression, characterised by the presence of anhedonia and general sadness, plus a range of other cognitive, physical or emotional symptoms [37]. Some of the brain-based aspects of depression link with its psychological symptoms, indicating that this disorder needs to be considered from a unified perspective. For example, depressed patients can exhibit: depressed mood, which may be associated with dysfunction of the activity of the left dorsolateral prefrontal cortex [49]; excessive guilt and hopelessness, which is linked with dysfunction of the hypothalamic-pituitary-adrenal (HPA) axis [50-53]; psychomotor agitation, loss of weight and sleep problems, perhaps reflecting abnormalities in the function of the thyroid axis [54]; and disturbances to Random Eye-Movement sleep, commonly caused by changes to circadian rhythms [55].

Most brain functions rely upon the presence of various neurotransmitters. Reduced availability of those neurotransmitters causes impaired cognitive performance and may lead to depression [56]. This process has been described as the "monoamine hypothesis" because it focuses upon the reduced presence of monoamine neurotransmitters in depressed persons, a state that is brought about via the degrading actions of monoamine oxidases in the synaptic cleft [56]. By applying anti-oxidase agents in the form of antidepressant medication, levels of monoamine neurotransmitters may be restored $[57,58]$. Serotonin, noradrenalin and dopamine are particularly important monoamine neurotransmitters that have been inculcated in depression [56]. Serotonin (or 5-HT) has the largest cohesive neurotransmitter system in the brain and innervates all brain areas [59]. Changes to serotonin have been shown to influence the core behavioural and somatic functions that underlie depression, such as appetite, sleep, sex, pain response, body temperature and circadian rhythm [60], and post-mortem studies indicate lowered levels of serotonin in the brains of depressed patients [61-63]. Noradrenalin is also a major neurotransmitter, with noradrenergic neurons spreading from the brain stem to almost all brain areas and modulating the function of the prefrontal cortex (which uses working memory to regulate behaviour and attention), as well as having an important role in the acquisition of emotionally-arousing memories [59]. Dopamine modulates activity in brain areas involved with reward and motivation, working memory and attention [64], and reduced dopamine has also been inculcated in the development of depression [65]. As may be expected, serotonin, noradrenalin and dopamine are primary targets for pharmacological treatments for depression.

Genetic bases for the reduced functionality of serotonin [66] and dopamine [67] have been established.
However, these genetic influences do not operate in a vacuum, and the interaction of environmental stress with genes has been shown to be reciprocal [68]. Adolescent depression develops via the experience of aversive environmental events and chronic stress during childhood, acting through prolonged HPA activation as indicated by elevated cortisol $[69,70]$ in those individuals who carry particular genes that are up-regulated by the adverse experiences of childhood. For example, early life adversity decreases expression by the gene for BrainDerived Neurotrophic Factor, which mediates neural plasticity in the prefrontal cortex (PFC) and hippocampus [71]. Interactions between environmental events and genetic predisposition to depression reduce neurogenesis in the hippocampus (an area which is centrally involved in the storage and accessing of memories that underlie emotional expression), thereby contributing to lowered mood and depression [46]. Taken together, these data provide support for the "Diasthesis-Stress hypothesis" $[72,73]$, under which interactions between the environment and genes lead to associated neurobiological and structural changes in the brain that are linked to depression [74-76]. The major pathway through which environmental adversity leads to gene-linked changes in neurotransmitter function, brain structure and thence depression, is the HPA axis.

\section{How the HPA axis links genes, environmental stress and depressive behaviour}

Hyperesponsivity of the HPA axis under stressful environmental conditions has been associated with depression in several studies [e.g., [50-53]]. When highly activated, the HPA axis produces elevated serum cortisol, leading to hypercortisolaemia, which can cause changes to those regions of the brain that are associated with cognitive processing of how threatening a particular environmental demand may be to the individual and how that threat might be dealt with (i.e., PFC and hippocampus), plus those regions which are centrally associated with intensifying emotional responses (i.e., amygdala) [77]. Specifically, these hypercortisolaemic effects include dendritic branching and neurogenesis which produce increases in the volume of the amygdala [78], and cell apoptosis which decreases the volumes of the PFC [79] and hippocampus [80]. There are also alterations to the connectivity of those regions of the brain, for example between the amygdala and the PFC [81] and between the amygdala and the hippocampus [82]. These organic changes to the brain have been linked to the eventual development of those withdrawal behaviours that underlie depressive symptomatology $[29,33]$. Those brain region and interconnectivity changes have been shown to be a direct outcome of hypercortisolaemia, and this pathway between 
environmental stressor-induced hyperactivation of the HPA axis and depression represents the neurobiological link between those stressors and the depressive symptomatology that is described in behavioural accounts of depression.

The accepted symptomatologies of depression (i.e., DSM, ICD) highlight the specific presence of apathy and anhedonia, which are localised to the reward circuits in the limbic system that are heavily reliant on dopamine [83], leading Nestler, et al. [76] to call that limbic reward system the "neural circuitry of depression" (p. 16). For example, amygdala blood flow increases, but PFC blood flow decreases, in depressed patients compared to non-depressed controls [84], supporting the finding that increases in amygdala function are related to depressive state [85]. In addition to this emotional aspect of depression, and because the PFC is a key area for motivation to change or adapt to demanding environments, damage to the PFC also impairs these resilience-oriented abilities, and apathy may develop. As mentioned above, apathy is the central symptom of depression [86], and prevents depressed individuals from taking action to reduce their unhappiness via more productive problem-solving and lifestyle strategies [37]. Thus, impairment of the PFC is directly linked to this key symptom of depression [87].

These structural changes to the amygdala, PFC and hippocampus also induce elevated anxiety behaviour, which may then instigate even greater elevation of hypothalamic responses to stress. When the individual is threatened, the activation of the amygdala stimulates the hypothalamus for fight-or-flight responses. By contrast, the hippocampus has an inhibitory effect upon the hypothalamus [88], principally via the involvement of its ventral region in inhibition of the sympathetic nervous system (SNS) and subsequent reduction of anxiety behaviours [89]. While anxiety may occur alone, it is often comorbid with depression [90], and there is also major overlap in the symptomatology for both disorders [91]. These links between hippocampal inhibition of anxiety and the amygdaloid activation of fear via hypothalamic neuroendocrine secretions may represent a "balance" of efforts by these two regions that has the effect of allowing the individual to manage threat effectively [92]. When that balance is disturbed by alterations to the hippocampus and amygdala (and their comparative influence on the hypothalamus), disturbances in mood follow, contributing to the likelihood of clinical depression.

These findings suggest a model of depression in which a circuit including the PFC, amygdala and hippocampus influences not only mood regulation, but also learning and contextual memory processes [88]. Specifically, during major depression the ventromedial prefrontal cortex
(VMPFC) and lateral orbital prefrontal cortex (LOPFC) are hyperactivated and the dorsolateral prefrontal cortex (DPFC) is hypoactivated [93,94]. These changes are consistent with the symptoms of major depression because hyperactivation of the VMPFC is associated with sensitivity to pain, anxiety, depressive rumination and tension, while hypoactivity of the DPFC is associated with psychomotor retardation, apathy, and deficits in working memory and attention [88]. Studies of the connectivity between these areas have also suggested that decreased communication between the amygdala and anterior cingulate complex (ACC) occurs in major depression [95]. Because the ACC acts to inhibit emotional regulation [89], decreases in communication between it and the amygdala could be involved in the irregularity of mood that is another symptom of depression [88].

These details are important in forming a causal chain that links environmental stressors to depressive behaviour because, when connectivity is disrupted between the integrative and executive functions of the lateral orbital PFC, rostral PFC, medial PFC, dorsolateral PFC and dorsal ACC on one hand, and the emotional/visceral functions of the ventral ACC and ventral medial PFC, plus the hippocampus, amygdala and nucleus accumbens on the other hand, the brain undergoes a decrease in regulatory feedback from the former "rational" regions to the latter "emotional" regions [92]. This allows the latter to dominate control of the hypothalamus and consequent neuroendocrine activity, leading to further stress responses and SNS dominance [77], plus increases in fear and consequent withdrawal by the fearful/depressed individual from their physical and social environment $[29,33]$.

\section{Explaining functional outcomes of depression from a behavioural-neurobiological perspective}

As indicated above, the amygdala enlarges and the PFC and hippocampus shrink either before or during the initial stages of depression, producing a more emotionoriented response pattern in the depressed individual, principally via elevated activation of the HPA axis, hypercortisolaemia, increased hypothalamic activity and downstream increases in SNS activity. Although this emotionality might initially appear to be at odds with the relatively "flat" affect that is symptomatic of depression, it may more easily fit within the early stage of depression, when the patient is faced with uncontrollable aversive environmental events. When faced with that kind of insurmountable environmental stressor, the relative usefulness of completely rational problem-solving strategies is probably low, simply because of the powerlessness experienced by the depressed individual when they consider their situation rationally. That is, compared to emotional responses that may enhance the 
individual's likelihood of (even by chance) finding a strategy out of the uncontrollable aversive situation they are in, rational thinking may be less likely to be selected by environmental pressures. In addition, these heightened emotional responses in the face of uncontrollable aversive stressors may result in the depressed individual becoming extremely frightened and even behaviourally "freezing" or withdrawing, and thereby avoiding further unwanted aversive outcomes. This phenomenon of "freezing" is common among mammals as a response to a predator and has a functional value in that it shows submission and hence may cause the predator to cease attacking $[96,97]$. Freezing may also perfor a valuable function because many predators' actions are triggered by movement, and they may lose interest when the prey remains motionless for some time, thus conveying a survival advantage upon the frozen prey [98]. Additionally, some predators do not eat dead meat and may refrain from eating prey that appears to be dead (i.e., immobile) [99]. Similar freezing behaviour has been reported in humans when faced with rape [100] and airline disasters [101], and has been described as "an evolutionary-based fear response" [102].

However, although several authors have described depression as "evolutionary" in that it has evolved to perform the functions of (1) withdrawing from uncontrollable aversive stressors and allowing the depressed individual time to analyse the stressful situation they find themselves in, and (2) eliciting assistance from partners and close others [102,103], this model is not without its critics $[104,105]$ and may also be misnamed on biological grounds because depressed individuals do not possess any visible reproductive advantage, nor do their offspring [106]. More accurately, depression might be considered to serve the immediate adaptive function of withdrawal in the face of uncontrollable aversive environmental stressors, i.e., it performs a function for the depressed person at the time of the stressor. That function may include reduction in the intensity of the environmental stressor's effect upon them, provision of time for reflection on future responses to the stressor, allowing time for the stressor to pass, and as a passive invitation to others to take some responsibility for the depressed individual's welfare. In more modern times, depression may also serve the individual by providing intense nurturing in the form of psychotherapy [107], reduction of the organic unpleasantness associated with depression via antidepressant medication [108], reduction of workload via formal sick-leave [109], and wider social support from family and friends.

When viewed from this perspective, the neurobiological responses of: (i) elevated HPA axis activation in response to overwhelming stressors, followed by consequent hypercortisolaemia, which causes (ii) structural alterations to the amygdala (enlargement) and PFC and hippocampus (shrinkage) that lead to (iii) amygdala dominance of the hypothalamus, causing (iv) more emotional and SNS-focussed behavioural activity patterns, can be understood as a chain of neuro-behavioural responses to threat that may possess some immediate benefit for the individual exhibiting them. Concomitantly to these adjustments to uncontrollable stress, emotional responses to such adversity engender some typical physiological responses including crying [37], an activity which secretes endorphins, thereby providing some relief from the depression, however transient [110]. Other physiological responses observed during depression include sleepiness (which provides respite from awareness of the aversive environmental stimuli), and compensatory behaviours such as overeating (which may be distracting and/or pleasant) $[37,107]$. Coupled with apathy, reduced interest or pleasure in activities relating to the stressful environment, and overall social and behavioural withdrawal, these observable phenomena comprise the major symptomatology of MDD.

\section{Using a behavioural-brain model in therapy: Implications for treatment}

As well as explaining the link between aversive environmental stressors, withdrawal (depressive) behaviour and escape, plus access to valued environmental consequences via functional analysis as described above, the range of behavioural therapies share the principal effective components of (i) building rapport between therapist and patient $[111,112]$, and (ii) behavioural homework activities which are recommended by therapists to help patients re-experience pleasure in daily activities [113]. Although beyond the scope of this paper, the wide range of behaviourally-oriented therapies, methods of establishing rapport and ways of enhancing generalisation of in-therapy cognitive changes to real-world behavioural change is recognised here. For the purposes of the major argument being proposed (i.e., that inclusion of neurological phenomena within those behavioural frameworks will enable therapists to understand how depression occurs), this wide range of approaches is subsumed under the term "behavioural therapies".

If accentuated, the first of these therapeutic strategies (i.e., therapeutic rapport) can provide a powerful oneon-one interpersonal rapport experience for the depressed person, and may reduce hypercortisolaemia [107]. Support for this hypothesis comes from the finding that some behavioural therapies reduce "waking cortisol" [114] which is significantly associated with depression [115]. An analogy may be drawn between the hypercortisolemia observed in depression and that 
brought about by a lack of maternal stimulation and care given to neonates who consequently develop HPAaxis hyperactivation [116] and are vulnerable to earlyonset depression during adolescence (although the potential for reversal of this is shown by hippocampal neurogenesis when maternal nurturance is reinstated [117]). Similarly, the intense verbal support and attention that is provided during psychological therapies may present a parallel nurturing experience for depressed patients who may previously have lost most sources of social reinforcement [107].

The second major strategy of behaviour therapies is that of behavioural activation, or encouraging the depressed person to engage in behaviours that will bring more positive social and personal enjoyment [113]. By replacing social-withdrawal behaviours with socialengagement behaviours, the previously-uncontrollable environmental stressor that instigated hypercortisolaemia (and its consequences to the PFC, hippocampus and amygdala that worked to help the depressed individual withdraw from their threatening environment), may become less important to the person facing it and therefore reduce the need for the accompanying (and functional) neurobiological sequence of withdrawal events that has been described above.

However, these neurobiological effects of behaviour therapies are valuable but often occur without the awareness of behaviour therapists. Based upon the links described above between environmental stressors, neurobiological sequelae, and overt behaviour, several other suggestions may be made so that behaviour therapists might actively incorporate neurobiological data into behaviourally-focussed therapies for depression. First, as well as standard psychological assessment and background information, induction to therapy for depression might include blood or saliva tests for hypercortisolaemia as an indicator of prolonged HPA activation that may lead to organic changes to the PFC, hippocampus and amygdala. Although more invasive, functional MRI assessments of those sections of the depressed patient's brain might also inform initial assessment and provide a baseline for evaluation after treatment. Second, although considered to be an important and existing aspect of those therapies, the level of rapport and support engendered in behavioural therapies should receive major attention because intense rapport has been shown to decrease cortisol (as described above). Therefore, this aspect of the patient-therapist interaction should be more than the superficial friendliness that is part of common professional demeanour [118-120]. Third, many depressed patients may experience depression following a tragic event such as death of a loved one, job loss, or a major personal injury that inhibits previouslyavailable activities. Although the DSM-IV-TR states that depression arising from some of these events is actually "understandable intense sadness" rather than clinical depression [37], patients' feelings are real to them and may be experienced by them as depression. By having the functional value of the neurobiological events that are detailed in this paper explained to them during therapy, depressed patients may accept that their "depression" (i.e., social withdrawal) is functional, and thus indicative of their overall adaptability to major loss rather than of mental illness. Fourth, although the behavioural activation aspect of therapy (i.e., via homework in the real world) is a significant factor in patient change under those therapeutic approaches [113], emphasis on the beneficial effects of those activities that are designed to help patients expose themselves to multiple sources of distraction and social nurturance might be augmented by explanations of how they can potentially re-establish normal HPA axis activation, reduce serum cortisol levels, renew PFC and hippocampal neurogenesis, and re-establish the "balance" between emotional and rational decision-making about environmental stress. Fifth, the use of behavioural coaching may be beneficial for clients who are currently unable to instigate self-helping behaviour that enhances their social reinforcers.

\section{Conclusion}

Although a wealth of research data support the use of behavioural models of depressive behaviour and behavioural therapies for treatment of depression, particularly those which emphasise a functional analysis component, the neurobiological underpinnings of the onset of depressive behaviour and its adaptive consequences for the person exhibiting it (and, consequentially, behavioural therapy approaches for treatment of depression) have not been joined in a comprehensive model. Built upon the notions of sickness behaviour as providing a benefit to the infected organism, the concomitant neurobiological alterations to structure and function of various brain regions (principally the PFC, hippocampus and amygdala) that accompany elevated HPA-axis activation following the onset of uncontrollable and highly aversive environmental stressors, may be seen to link observable behaviour with brain function to provide a more comprehensive model of depression. Further exploration of this model via monitoring of brain function during depressive experiences and therapy may help provide more detail for this model and move it towards greater completeness.

\section{Author details}

${ }^{1}$ Brain-Behaviour Research Group, University of New England, New South Wales, Australia. ${ }^{2}$ Brain-Behaviour Research Group, Bond University, Queensland, Australia. 


\section{Authors' contributions}

CS conceived the concept and designed the overall paper. He also wrote the sections on neurobiology of depression and about the ways in which the HPA axis links genes, environmental stress and depressive behaviour. VB wrote the section regarding behavioural therapies and functional analysis in depression, and also how the behavioural-brain model could be used in therapy. Both authors approved the final ms.

CS.

Both authors read and approved of the complete ms.

\section{Authors' information}

VB is Associate Professor of Clinical Psychology and Behaviour Management, a State-Registered Clinical Psychologist, and has interests in behavioural and functional analysis of therapies for depression.

CS is a Professor of Clinical Neuroscience, with interests in the biological underpinnings of depression and treatment modalities.

\section{Competing interests}

Financial competing interests: The author(s) declare that they have no competing financial interests.

Non-financial competing interests: The author(s) declare that they have no competing non-financial interests.

Received: 10 October 2010 Accepted: 11 December 2010

Published: 11 December 2010

\section{References}

1. Nutt D: Anxiety and depression: Individual entiteis or two sides of the same coin? International Journal of Psychiatry in Clinical Practice 2004, 8:19-24.

2. Druss BG, Rosenheck RA: Patterns of Health Care Costs Associated With Depression and Substance Abuse in a National Sample. Psychiatric Services 1999, 50:214-218.

3. Judd LL, Paulus MP, Wells KB, Rapaport MH: Socioeconomic burden of subsyndromal depressive symptoms and major depression in a sample of the general population. American Journal of Psychiatry 1996, 163:1411-1417.

4. Lyness JM, Heo M, Datto CJ, Ten Have TR, Katz IR, Drayer R, Reynolds CF, Alexopoulos GS, Bruce ML: Outcomes of Minor and Subsyndromal Depression among Elderly Patients in Primary Care Settings. Annals of Internal Medicine 2006, 144:496-504.

5. Ustun TB, Ayuso-Mateos JL, Chatterji S, Mathers C, Murray CJL: Global burden of depressive disorders in the year 2000. British Journal of Psychiatry 2004, 184:386-392.

6. Murray CJ LA: Alternative projections of mortality and disability by cause 1990-2020: Global burden of disease study. Lancet 1997, 349:1498-1504.

7. WHO: Cross-national comparisons of the prevalences and correlates of mental disorders. WHO International Consortium in Psychiatric Epidemiology. Bulletin of the World Health Organisation 2001, 78.

8. Mykletun A, Bjerkeset O, Øverland S, Prince M, Dewey M, Stewart R: Levels of anxiety and depression as predictors of mortality: the HUNT study. British Journal of Psychiatry 2009, 195:118-125.

9. Alonso J, Angermeyer MC, Bernert S, Bruffaerts R, Brugha TS, Bryson H, de Girolamo G, de Graaf R, Demyttenaere K, Grasquet I, et al: Prevalence of mental disorders in Europe: results from the European Study of the Epidemiology of Mental Disorders (ESEMeD) project. Acta Psychiatrica Scandinavica 2004, 109:21-27.

10. Kessler R, Berglund P, Borges G, Nock M, Wang P: Trends in suicide ideation, plans, gestures, and attempts in the United States. The Journa of the American Medical Association 2005, 293:2488-2495.

11. Kessler R, McGonagle K, Shanyang Z, Nelson C, Hughes M, Eshleman S, et al: Lifetime and 12-month prevalence of DSM-III-R psychiatric disorders in the United States: Results from the National Comorbidity Survey. Archives of General Psychiatry 1994, 51:8-19.

12. Hollon S, Thase M, Markowitz J: Treatment and prevention of depression. Psychological Science and the Public Interest 2002, 2:39-77.

13. Cuijpers P, van Straten A, Anderson G, van Oppen P: Psychology for Depression in Adults: A Meta-Analysis of Comparative Outcomes Studies. Journal of Consulting and Clinical Psychology 2008, 76:909-922.

14. Schatzberg AF, Rush AJ, Arnow BA, Banks PLC, Blalock JA, Borian FE, Howland R, Klein DN, Kocsis JH, Kornstein SG, et al: Chronic Depression -
Medication (Nefazodone) of Psychotherapy (CBASP) Is Effective When the Other Is Not. Archives of General Psychiatry 2005, 62:513-520.

15. Kocsis JH, Gelenberg AJ, Rothbaum BO, Klein DN, Trivedi MH, Manber R, Keller MB, Leon AC, Wisniewski SR, Arnow BA, et al: Cognitive Behavioral Analysis System of Psychotherapy and Brief Supportive Psychotherapy for Augmentation of Antidepressant Nonresponse in Chronic Depression: The REVAMP Trial. Arch Gen Psychiatry 2009, 66:1178-1188.

16. Ekers $D$, Richards $D$, Gilbody S: A meta-analysis of randomized trials of behavioural treatment of depression. Psychological Medicine 2008, 38:611-623.

17. Thase ME: Atypical Depression: Useful Concept, but it's Time to Revise the DSM-IV Criteria. Neuropsychopharmacology 2009, 34:2633-2641.

18. Thase MES, Cahalane AD, JF McGeary J: Cognitive behavior therapy of endogenous depression: Part 1: An outpatient clinical replication series. Behavior Therapy 1991, 22:457-467.

19. Minors-Wallace LM, Gath DH, Day A, Baker F: Randomised controlled trial of problem solving treatment, antidepressant medication, and combined treatment for major depression in primary care. British Medical Journal 2000, 320:26-30.

20. Ruggiero KJ, Morris TL, Hopko DR, Lejuez CW: Application of Behavioral Activation Treatment for Depression to an Adolescent With a History of Child Maltreatment. Clinical Case Studies 2007, 6:64-78.

21. Hayes S, Masuda A, Bissett R, Luoma J, Guerrero L: DBT, FAT and ACT: How empirically oriented are the new behavior therapy technologies? Behavior Therapy 2004, 35:35-54.

22. Thase ME, Denko T: Pharmacotherapy of Mood Disorders. Annual Review of Clinical Psychology 2008, 4:53-91.

23. Luty SE, Carter JD, McKenzie JM, rae AM, Frampton CMA, Mulder RT, Joyce PR: Randomised controlled trial of interpersonal psychotherapy and cognitive-behavioural therapy for depression. British Journal of Psychiatry 2007, 190:496-502.

24. DeRubeis RJ, Gelfand LA, Tang T, Simons A: Medications versus cognitive behavior therapy for severely depressed outpatients: Mega-analysis of four randomized comparisons. American Journal of Psychiatry 1999, 156:1007-1013.

25. DeRubeis RJ, Hollon SD, Amsterdam JD, Shelton RC, Young PR, Salomon RM, O'Reardon JP, Lovett ML, Gladis MM, Brown LL, Gallop R: Cognitive Therapy vs Medications in the Treatment of Moderate to Severe Depression. Archives of General Psychiatry 2005, 62:409-416.

26. Schatzberg A, Rush A, Arnow B, Banks P, Blalock J, Borian F, Howland R, Klein DN, Kocsis JH, Kornstein SG, et al: Medication (Nefazodone) or psychotherapy (CBASP) is effective when the other is not. Archives of General Psychiatry 2005, 62:513-520.

27. Kohlenberg RJ, Tsai M: Functional Analytic Psychotherapy: Creating Intense and Curative Therapeutic Relationships New York: Plenum Press; 1991.

28. Sturmey P: Functional analysis in clinical psychology New York: John Wiley \& Sons; 1996

29. Bolling MY, Kohlenberg RJ, Parker CR: Behavior Analysis and Depression. In Clinical Behavior Analysis. Edited by: Dougher MJ. Reno, Nevada: Context Press; 1999:127-153.

30. Darwin C: Recollections of the development of my mind and character. Autobiographies London: Penguin;1876-2002.

31. Ferster CB: A Functional Analysis of Depression. American Psychologist 1973, 28:857-870.

32. Dougher MJ, Hackbert L: A Behavior-Analytic Account of Depression and a Case Report Using Acceptance-Based Procedures. The Behavior Analyst 1994, 17:321-334.

33. Kanter JW, Busch AM, Weeks CE, Landes SJ: The Nature of Clinical Depression: Symptoms, Syndromes, and Behavior Analysis. The Behavior Analyst 2008, 31:1-21.

34. Dantzer R, O'Connor JC, Freund GG, Johnson RW, Kelley KW: From information to sickness and depression: when the immune system subjugates the brain. Nature Reviews Neuroscience 2007, 9:45-56.

35. Konsman J, Vigues S, Mackerlova L, Bristow A, Blomqvist A: Rat brain vascular distribution of interleukin-1 type-1 receptor immunoreactivity: relationship to parretns of inducible cyclooxygenase expression by peripheral inflammatory stimuli. Journal of Comparative Neurology 2004, 472:113-129.

36. Parnet $P$, Kelley $K$, Bluthe R, Dantzer R: Expression and regulation of interleukin-1 receptors in the brain. Role in cytokines-induced sickness behavior. Journal of Neuroimmunology 2002, 125:5-14. 
37. APA: Diagnostic and Statistical Manual of Mental Disorders (4th ed, Text Revision) Washington, DC: American Psychiatric Association; 2000.

38. Gilbert P: Evolution and depression: issues and implications. Psychological Medicine 2006, 36:287-297.

39. Gilbert P: Evolutionary psychopathology: Why isn't the mind designed better than it is? British Journal of Medical Psychology 1998, 71:353-373.

40. Kanter JW, Cautilli JD, Busch AM, Baruch DE: Toward a Comprehensive Functional Analysis of Depressive Behavior: Five Environmental Factors and a Possible Sixth and Seventh. The Behavior Analyst Today 2005, 6:65-81.

41. Kohlenberg RJ, Kanter JW, Bolling MY, Parker CR, Tsai M: Enhancing Cognitive Therapy for Depression With Functional Analytic Psychotherapy: Treatment Guidelines and Empirical Findings. Cognitive and Behavioral Practice 2002, 9:213-229.

42. Sanacora G, Mason GF, Krystal JH: Impairment of GABAergic Transmission in Depression: New Insights from Neuroimaging Studies. Critical Reviews in Neurobiology 2000, 14:23-45.

43. Sullivan PF, de Geus EJC, Willemsen G, James MR, Smit JH, Zandbelt T, Arolt V, Baune BT, Balckwood D, Cichon S, et al: Genome-wide association for major depression disorder: a possible role for the presynaptic protein piccolo. Molecular Psychiatry 2009, 14:359-375.

44. Uher $\mathrm{R}$ : The implications of gene-environment interactions in depression: will cause inform cure? Molecular Psychiatry 2008, 13:1070-1078.

45. Uher R, McGuffin P: The moderation by the serotonin transporter gene of environmental adversity in the aetiology of mental illness: review and methodological analysis. Molecular Psychiatry 2008, 13:131-146.

46. Mirescu C, Gould E: Stress and Adult Neurogenesis. Hippocampus 2006, 16:233-238.

47. Hettema JM, An SS, Bukszar J, van den Oord EJ, Kendler KS, Chen X: Association between glutamic and decarboxylase genes and anxiety disorders, major depression, and neuroticism. Molecular Psychiatry 2006, 11:752-762.

48. Lopez-Leon S, Janssens ACJW, Gonzalez-Zuloeta Ladd AM, Del-Favero J, Claes SJ, Oostra BA, van Duijn CM: Meta-analysis of genetic studies on major depressive disorder. Molecular Psychiatry 2008, 13:772-785.

49. Galynker II, Cai J, Ongsengg F, Finsetone H, Dutta E, Serseni D: Hypofrontality and negative symptoms in major depressive disorder. Journal of Nuclear Medicine 1998, 39:608-612.

50. Du J, Wang Y, Hunter R, Wei Y, Blumenthal R, Falke C, Khairova R, Zhou R, Yuan P, Machado-Viera $R$, et al: Dynamic regulation of mitochondrial function by glucocorticoids. Proceedings of the National Academy of Sciences 2009, 106:3543-3548

51. Fiocco AJ, Wan N, Weekes N, Pim H, Lupien SJ: Diurnal cycle of salivary cortisol in older adults men and women with subjective complaints of memory deficits and/or depressive symptoms: Relation to cognitive functioning. Stress 2006, 9:143-152.

52. Gillespie CF, Nemeroff CB: Hypercortisolemia and Depression. Psychosomatic Medicine 2005, 67:S26-S28.

53. Segerstrom SC, Miller GE: Psychological Stress and the Human Immune System: A Meta-Analytic Study of 30 Years of Inquiry. Psychological Bulletin 2004, 130:601-630.

54. Thase ME, Howland RH: Biological processes in depression: An updated review and integration. In Handbook of depression. Edited by: Beckham EE, Leber WR. New York: Guilford; 1995:213-279.

55. Rush A, Giles DE, Schlesser MA, Orsulak P, Weissenburger J, Fulton CL, al. e: Dexamethasone response, thyrotropin-releasing hormone stimulation, rapid eye movement latency, and subtypes of depression. Biological Psychiatry 1997, 41:915-928.

56. Rang HP, Dale MM, Ritter J, Flower RJ: Pharmacology. 6 edition. Philadelphia: Elsevier; 2007.

57. Coppen A: The biochemistry of affective disorders. British Journal of Psychiatry 1967, 113:1237-1264.

58. Schildkraut JJ: The catecholamine hypothesis of affective disorders: A review of supporting evidence. American Journal of Psychiatry 1965, 122:509-522.

59. Delgardo P, Morena F: Neurochemistry of mood disorders. In The textbook of mood disorders. Edited by: Stein DK, Kupfer DJ, Schatzberg AF. Washington DC: American Psychiatric Publishing Inc; 2006:101-116.

60. Maes M, Meltzer $\mathrm{H}$ : The serotonin hypothesis of major depression. In Psychopharmacology: The fourth generation of progress. Edited by: Bloom FE, Kupfer DJ. New York: Raven; 1995:933-944
61. Perry EK, Marshall EF, Blessed G, Tomlinson BE, Perry RH: Decreased imipramine binding in the brains of patients with depressive illness. British Journal of Psychiatry 1983, 142:188-192.

62. Stanley M, Virgilio J, Gershon S: Tritiated imipramine binding sites are decreased in the frontal cortex of suicides. Science 1982, 216:1337-1339.

63. Stockmeier CA: Involvement of serotonin in depression: evidence from postmortem and imaging studies of serotonin receptors and the serotonin transporter. Journal of Psychiatric Research 2003, 37:357-373.

64. Chen L, Zhuang X: Transgenic mouse models of dopamine deficiency. Annals of Neurology 2003, 54:S91-S102.

65. Willner P: Dopamine and depression: A review of recent evidence, I: Empirical studies. Brain Research 1983, 6:211-224.

66. Muller N, Schwartz MJ: The immune-mediated alteration of serotonin and glutamate: Towards an integrated view of depression. Molecular Psychiatry 2007, 12:988-1000.

67. Choudary P, Molnar M, Evans SJ, Tomita H, Li JZ, Vawter MF, et al: Altered cortical glutamatergic and GABAergic signal transmission with glial involvement in depression. Proceedings of the National Academy of Sciences 2005, 102:15653-15658.

68. Phillips H: How life shapes the brainscape. Book How life shapes the brainscape (Editor ed.^eds.) 2005, 12-13, City 12-13.

69. Rao U, Hammen CL, Ortiz LR, Chen L-A, Poland RE: Effects of Early and Recent Adverse Experiences on Adrenal Response to Psychological Stress in Depressed Adolescents. Biological Psychiatry 2008, 64:521-526.

70. Tyrka AR, Wier L, Price LH, Ross N, Anderson GM, Wilkinson CW, Carpenter LL: Childhood Parental Loss and Adult Hypothalamic-PituitaryAdrenal Function. Biological Psychiatry 2008, 63:1147-1154.

71. Roth TL, Lubin FD, Funk AJ, Sweatt JD: Lasting Epigenetic Influence of Early-Life Adversity on the BDNF Gene. Biological Psychiatry 2009, 65:760-769.

72. Barlow D, Durand V: Abnormal Psychology Pacific Grove: Brooks/Cole; 1995

73. Bear M, Connors B, Paradiso M: Neuroscience: Exploring the brain. 3 edition. Baltimore, MD: Lippincott, Williams \& Wilkins; 2007.

74. Charney DS: Psychobiological Mechanisms of resilience and Vulnerability: Implications for Successful Adaptation to Extreme Stress. Focus 2004, 2:368-391

75. Charney DS, Manji HK: Life Stress, Genes, and Depression: Multiple Pathways Lead to Increased Risk and New Opportunities for Intervention. Science Signaling - The Signal Transduction Knowledge Environment 2004, re5.

76. Nestler EJ, Barrot M, DiLeone RJ, Elsch AJ, Gold SJ, Monteggia LM: Neurobiology of Depression. Neuron 2002, 34:13-25.

77. Chrousos GP: Stress and disorders of the stress system. Nature Reviews Endocrinology 2009, 5:374-381.

78. van Eijndhoven P, van Wingen G, van Oijena K, Rijpkemad M, Gorajb B, Verkesa R, Voshaara R, Fernándezc G, Buitelaara J, Tendolkara I: Amygdala volume marks the acute state in early course of depression. Biological Psychiatry 2009, 65:812-818.

79. Levin RL, Heller W, Mohanty A, Herrington JD, Miller GA: Cognitive Deficits in Depression and Functional Specificity of Regional Brain Activity. Cognitive Therapy and Research 2007, 31:211-233.

80. MacQueen GM, Yucel K, Taylor VH, Macdonald K, Joffe R: Posterior Hippocampal Volumes Are Associated with Remission Rates in Patients with Major Depressive Disorder. Biological Psychiatry 2008, 64:880-883.

81. de Almeida JRC, Versace A, Mechelli A, Hassel S, Quevedo K, Kupfer DJ, Phillips ML: Abnormal Amygdala-Prefrontal Effective Connectivity to Happy Faces Differentiates Bipolar from Major Depression. Biological Psychiatry 2009, 66:451-459.

82. Fu CHY, Williams SCR, Cleare AJ, Scott J, Mitterschiffthaler MT, Walsh ND, Donaldson C, Suckling J, Andrew C, Steiner H, Murray RM: Neural Responses to Sad Facial Expressions in Major Depression Following Cognitive Behavioral Therapy. Biological Psychiatry 2008, 64:505-512.

83. Lieberman A: Depression in Parkinson's Disease - a review. Acta Neurologica Scandinavica 2006, 113:1-8.

84. Siegle GJ, Thompson W, Carter CS, Steinhauer SR, Thase ME: Increased Amygdala and Decreased Dorsolateral Prefrontal BOLD Responses in Unipolar Depression: Related and Independent Features. Biological Psychiatry 2007, 61:198-209.

85. Quirk GJ, Gehlert DR: Inhibition of the Amygdala: Key to Pathological States? Annals of the New York Academy of Science 2006, 985:263-272. 
86. Nitschke JB, Mackiewicz KL: Prefrontal and Anterior Cingulate Contributions to Volition in Depression. International Review of Neurobiololy 2005, 67:73-94.

87. Schlosser RGM, Wagner G, Koch K, Dahnke R, Reinchenbach JR, Sauer $H$ : Fronto-cingulate effective connectivity in major depression: A study with fMRI and dynamic causal modeling. Neurolmage 2008, 43:645-655.

88. Maletic V, Robinson M, Oakes T, lyengar S, Ball SG, Russell J: Neurobiology of depression: an integrated view of key findings. International Journal of Clinical Practice 2007, 61:2030-2040.

89. Whittle S, Allen NB, Lubman DI, Yucel M: The neurobiological basis of temperament: Towards a better understanding of psychopathology. Neuroscience and Biobehavioral Reviews 2006, 30:511-525.

90. Coryell W, Endicott J, Andreason N, Keller M, Clayton J, Hirschfeld R, Scheftner W, Winokurtry G: Depression and panic attacks: The significance of overlap as reflected in follow-up and family study data. American Journal of Psychiatry 1988, 145:293-300.

91. Zinbarg RE, Barlow DH, Liebowitz M, Street L, Broadhead E, Katon W, RoyByrne P, Lepine J-P, Teherani M, Richards J, et al: The DSM-IV Field Trial for Mixed Anxiety-Depression. The American Journal of Psychiatry 1994, 151:1153-1162.

92. Roozendaal B, McEwan BS, Chattarji S: Stress, memory and the amygdala. Nature Reviews Neuroscience 2009, 10:423-433.

93. Drevets W, Videen T, Price J, Preskorn S, Carmichael S, Raichle M: A functional anatomical study of unipolar depression. Journal of Neuroscience 1992, 12:3628-3641.

94. Drevets WC, Price JL, Bardgett ME, Reich T, Todd RD, Raichle ME: Glucose metabolism in the amygdala in depression: Relationship to diagnostic subtype and plasma cortisol levels. Pharmacology, Biochemistry and Behavior 2002, 71:431-447.

95. Anand A, Li Y, Wang Y, Wu J, Gao S, Bukhari L, Mathews VP, Kalnin A, Lowe MJ: Activity and Connectivity of Brain Mood Regulating Circuit in Depression: A Functional Magnetic Resonance Study. Biological Psychiatry 2005, 57:1079-1088.

96. Hennig C: Tonic immobolity in the squirrel monkey. Primates 1978, 19:333-342.

97. Rattner S: Comparative aspects of hypnosis. In Handbook of clinical and experimental hypnosis Edited by: Gordon J. New York: Macmillan 1967, 550-587.

98. Ewell A, Cullen J: Tonic immobility as a predator-defense in the rabbit (Oryctolagus cuniculus). Behavioral and Neural Biology 1981, 31:483-489.

99. Marks I: Fears, phobias, and rituals: Panic, anxiety, and their disorders New York: Oxford University Press; 1987.

100. Galliano G, Noble L, Travis $L$, Puechi C: Victim reactions during rape/sexual assault: A preliminary study of the immobility response and its correlates. Journal of Interpersonal Violence 1993, 8:109-114.

101. Gallup G, Rager D: Tonic immobility as a model of extreme stress of behavioral inhibition: Issues of methodology and measurement. In Motor activity and movement disorders. Edited by: Kavaliers M. Totowa, NJ: Humana Press; 1996:57-80.

102. Moskowitz AK: "Scared Stiff": Catatonia as an Evolutionary-Based Fear Response. Psychological Review 2004, 111:984-1002.

103. Watson PJ, Andrews PW: Toward a revised evolutionary asaptationist analysis of depression: the social navigation hypothesis. Journal of Affective Disorders 2002, 72:1-14.

104. Hendrie CA, Pickles AR: Depression as an evolutionary adaptation: Implications for the development of preclinical models. Medical Hypotheses 2009, 71:342-347.

105. Burns JK: Reconciling 'the new epidemiology' with an evolutionary genetic basis for schizophrenia. Medical Hypotheses 2009, 72:353-358.

106. Sharpley C, Bitsika V: Is Depression "Evolutionary" or just "Adaptive"? A comment. Depression: Research \& Treatment 2010.

107. Sharpley C: A Review of the Neurobiological Effects of Psychotherapy for Depression. Psychotherapy: Research, Training, Practice.

108. Rang HP, Dale MM, Ritter JM, Flower R: Rang and Dale's Pharmacology. 6 edition. Phil. PA: Elsevier; 2007.

109. Kemp PA, Davidson J: Routes onto Incapacity Benefit: Findings from a survey of recent claimants York: University of York - Social Policy Research Unit; 2007.

110. Panksepp J: Affective neuroscience New York: Oxford University Press; 1998.

111. Hawley LL, Ho M-HR, Zuroff DC, Blatt SJ: The relationship of perfectionism, depression, and therapeutic alliance during treatment for depression:
Latent difference score analysis. Journal of Consulting and Clinical Psychology 2006, 74:930-942.

112. Weisz JR, Southam-Gerow MA, Gordis EB, Connor-Smith JK, Chu BC, Langer DA, McLeod BD, Jensen-Doss A, Updegraff A, Weiss B: Cognitivebehavioral therapy versus usual clinical care for youth depression: An initial test of transportability to community clinics and clinicians. Journal of Consulting and Clinical Psychology 2009, 77:383-396.

113. Jacobson NS, Dobson KS, Truax PA, Addis ME, Koerner K, Gollan JK, Gortner E, Prince SE: A Component Analysis of Cognitive-Behavioral Treatment for Depression. Journal of Consulting and Clinical Psychology 1996, 64:295-304.

114. Mommersteeg PMC, Heijnen CJ, Keijsers GPJ, Verbraak MJPM, van Doornen LJP: Cortisol Deviations in People With Burnout Before and After Psychotherapy: A Pilot Study. Health Psychology 2006, 25:243-248.

115. Huber TJ, Issa K, Schik G, Wolf OT: The cortisol awakening response is blunted in psychotherapy inpatients suffering from depression. Psychoneuroendocrinology 2006, 31:900-904.

116. Weaver IC: Epigenetic effects of glucocorticoids. Seminars in Fetal \& Neonatal Medicine 2009, 14:143-150.

117. Weaver IC, Meaney MJ, Szyf M: Maternal care effects on the hippocampal transcriptome and anxiety-mediated behaviors in the offspring that are reversible in adulthood. Proceedings of the National Academy of Sciences 2006, 103:3480-3485.

118. Horvath A, Greenberg L: Development and validation of the Working Alliance Inventory. Journal of Counseling Psychology 1989, 36:223-233.

119. Horvath A, Symonds B: Relation between working alliance and outcome in psychotherapy: A meta-analysis. Journal of Counseling Psychology 1991 38:139-149.

120. Horvath $A O$, Luborsky $L$ : The role of the therapeutic alliance in psychotherapy. Journal of Consulting \& Clinical Psychology 1993, 61:561-573.

doi:10.1186/1744-9081-6-73

Cite this article as: Sharpley and Bitsika: Joining the dots: neurobiological links in a functional analysis of depression. Behavioral and Brain Functions 2010 6:73.

\section{Submit your next manuscript to BioMed Central and take full advantage of:}

- Convenient online submission

- Thorough peer review

- No space constraints or color figure charges

- Immediate publication on acceptance

- Inclusion in PubMed, CAS, Scopus and Google Scholar

- Research which is freely available for redistribution

Submit your manuscript at www.biomedcentral.com/submit
C) Biomed Central 